\title{
ERGONOMICS EVALUATION IN DESIGNED MAINTAINABILITY: CASE STUDY USING 3 DSSPP
}

\author{
Kiumars TEYMOURIAN, Phillip TRETTEN \\ Luleå University of Technology \\ Dammika SENEVIRATNE \\ TECNALIA, Basque Research and Technology Alliance (BRTA) \\ Diego GALAR \\ Luleå University of Technology \\ TECNALIA, Basque Research and Technology Alliance (BRTA)
}

\begin{abstract}
:
Maintainability is one of the design parameters (reliability, availability, maintainability, and safety (RAMS)) and maintenance is needed to keep the respective design in sustainable use. At the same time, the human is involved in the form of interface and interaction in an engineered product/system designed. Ergonomics is a multi-disciplinary science that considers human capabilities and limitations in a broader sense. The objective of this paper is to integrate ergonomics into the maintainability design process in order to facilitate maintenance operation in lesser; time, cost, easier operation as well as the well-being of human who is involved. In other words, good ergonomics lead to good economics and in a broader sense, sustainability. This investigation shows that designing comfortable workplaces and lesser workload for maintenance operators will be beneficial for the maintainability design process and also improve the meantime to repair MTTR. In order to evaluate the effect of designed workplace and workload on maintainers 3 D Static Strength Prediction Program (3D SSPP) that is commonly used as an ergonomics evaluation tool in scientific studies was applied.
\end{abstract}

Key words: maintainability, ergonomics, low back compression, 3D Static Strength Prediction Program

\section{INTRODUCTION}

Nowadays, as technologies become more advanced and complex, in order to maintain them maintenance operations will become more complex. Consequently, more physical and mental strain exertions will be for maintenance staff. No matter how the advanced system or industrial machines are, still, maintenance operations can cause a noteworthy amount of injuries each year. Maintenance performance influence workers' health and safety. In the report of maintenance and occupational safety and health (European Agency for Safety and Health at Work) [39] stated maintenance workers exposed to many physical hazards like; carrying heavy materials, pushing, pulling taking unnatural postures like bending, reaching kneeling and performing their tasks in small working environments. In this report stated, maintenance workers' disease rate is 10 times higher than other workers are, and around $10-15 \%$ of all fatal accidents were related to maintenance operations in 2006.

According to data reported in Finland, between 1994 and 2004 , the number of the severe accident were 90 for maintenance full-time staff [35]. These accidents resulted in injuries to the upper limbs (39\%) and at the same time $(28 \%)$ to several body parts and $(40 \%)$ of accidents associated with inappropriate or incongruous work instructions. Furthermore [35] it reported 33 occurred accidents led to fatalities during both planned operation and unscheduled repairs in industrial maintenance during 1985-2004.

As reported, in the United States by the center for disease control from 2003 to 2008 a total of 1142 grounds maintenance workers fatally injured (an average of 190 fatal injuries per year) [10]. Maintenance operations most associated with musculoskeletal ill health, the most frequent troubles were identified in the shoulder, knee, ankles and 
feet, wrist, and hand, neck, and especially the back Riley 2006 [46].

As the European Agency for Safety and Health at Work [39] described, lifting loads in awkward posture because of badly designed and no lifting devices can result in back problems which in turn leads to musculoskeletal disorders (MSD) for maintenance workers. Lifting load must be considered as a potential hazard, and the human low back is not structurally designed for manual lifting activities Chaffin et, al. [12]. Whereas, a study shown maintenance operators, represent the largest group of (approximately $40 \%$ ) of all reported work-related to musculoskeletal disorders in Norway's offshore petroleum industry Tone Morken et, al. [41]. Other studies show that awkward trunk posture during work can result in fatigue which leads to pain and disorders in the lower back William Monroe et al. [32]. Lakhwinder Pal Singh [49] did a posture analysis in the casting industry in India and he stated awkward posture and manual material handling can be eliminated through adaptation of ergonomics solutions like lifting assistance in order to decrease the risk of injuries and musculoskeletal disorders.

Christina Sedlatschek [47] the director of the European Agency for Safety and Health at Work stated, "Maintenance has to be done, but it has to be done in a safe way. The figures on maintenance-related accidents and exposures show that there is room for improvement." The above literature survey shows the seriousness of how maintenance workers are exposed to a variety of risks. In order to minimize or eliminating these risks, it is necessary to re-thinking in the earlier stages for maintenance planning and performance in the maintainability design process. All these risks need to be considered during the maintainability design process and planning of maintenance. Therefore, defects or imperfections in maintainability design and planning for maintenance operations processes not only create an indirect economic risk by jeopardizing the production continuity also confronting maintenance crew in danger.

Manual material handling can lead to muscular fatigue $\mathrm{NIOSH}[20]$. As $\mathrm{NIOH}$ described [20] muscular fatigue is the result of posture taken during and after manual material handling. Ciba foundation symposium [44], defined fatigue, as a failure to maintain the required or expected force in muscle, and the force of a voluntary contraction is graded according to both the tension generated in each muscle fiber and the number of fibers recruited (P. $11 \mathrm{Hu}$ man muscle fatigue: physiological mechanisms) and one the possible meaning of fatigue also is impaired intellectual performance. As Gandevia et al, [17] stated fatigue cause loss of muscles force and slowing down muscle's capability for producing contraction, and NIOSH [20] described when the muscles get fatigued they are no longer able to do effective work, also as Liang et al. [36] stated fatigue will reduce the joints strength, and in the study that did by Fang et, al. [14], shown fatigue slowing down body movement, and as Gerald et, al. [37] stated fatigue decrements in performance.
In this article, the relationship between maintainability, maintenance, and ergonomics for system/product design and their effect on humans are discussed and 3D Static Strength Prediction Program (3D SSPP) was used in order to evaluate low back compression during maintenance operations.

\section{MAINTAINABILITY}

ISO-Standard [51] define maintainability as, "the ability of an item under given conditions of use, to be retained in, or restored to, a state in which it can perform a required function when maintenance is performed under given conditions and using stated procedures and resources". U.S. Department of Defense [40] defined maintainability as; "The relative ease and economy of time and resources with which an item can be retained in or restored to a specified condition when maintenance is performed by personnel having specified skill levels, using prescribed procedures and resources, at each prescribed level of maintenance and repair. In this context, it is a function of design". Blanchard [42], "maintainability pertains to ease, accuracy, safety, and economy in the performance of maintenance actions". He (Blanchard [42] stated maintainability is a design parameter while maintenance is required as a consequence of design.

Safety and human engineering are two parts among five key disciplines (manufacturing, human engineering, diagnostics and maintenance, logistics support, and safety) in the handbook of maintainability design, Blanchard [42].

Dhillon [13] stated, maintainability is more dependent on the interactions between maintainers and machines author also stated maintainability depends more on human factors rather than reliability, and lack of careful consideration of human factors will result to increase problems for maintenance action and consequently reducing system/product effectiveness and readiness.

Bernard [7] in his study on the human factor in aeronautical maintainability, for the maintenance activity, stated maintainability performers use tools that are not related to ergonomics expertise, and after discussion with maintainability actors they became aware to concern the need to integrate ergonomics in their process design. This indicates as Hendrick in Handbook of human factors and ergonomics methods [50] stated after the equipment or software is designed ergonomist called to modify some of the human system interfaces for reducing the likelihood of human error, improving comfort, or eliminating awkward postures and because of this process, the outcome of ergonomist efforts will be suboptimal for work system. This is a result of a technology-centered approach to the design process.

This approach may have insufficient considerations of human factors aspects; the interface, interaction, limitation, and the capability which in turn, it may lead to deficiencies in reliability, availability, maintainability, and safety (RAMS) parameters. Hendrick stated in this approach (technology-centered) employees are not actively involved throughout the planning and implementation process [50]. Therefore effective interventions of ergonomics/human factors in the earlier design process will result 
in significant cost saving Stanton [50]. In this regard, as it is shown in Table 1 the ergonomics portion of the engineering budget can vary at different stages of developing a system/product, [23] and [2].

Table 1

The cost of using ergonomics in design

\begin{tabular}{lc}
\hline Stage of development & $\begin{array}{c}\text { The portion of the engineering } \\
\text { budget (\%) }\end{array}$ \\
\hline Early design & $1-2.5$ \\
Blueprint & $1-3.0$ \\
Construction & $2-6.5$ \\
Commissioning & $4-10.5$ \\
Normal operations & $5-12+$ \\
\hline
\end{tabular}

Source: [24].

Table 1 reveals if qualified ergonomist(s) participate in design group activities (during design process) in the earliest stage of product/system and maintainability design, it will results in not only the less costly the product/system will be, what's more, this participation will lead appreciatively on the cost-benefit or costs-savings for the entire life cycle of system/product.

Blanchard [42] stated the cost of acquiring a product is less than the ownership over the product's life cycle and it can be up to $75 \%$ of the total life cycle cost, and Dhillon [13] in some cases, it may increase up to 10 to 100 times of original product acquisitions. This can be the result of inappropriate technical and human factors considered in system/product design. Blanchard [42] stated life cycle cost is an important aspect when it comes to analysis maintainability for operation and maintenance, and he described that life cycle cost can be reduced from the earlier stages; from concept, advance planning, production, and the construction phases.

In the case of human-oriented design as shown in Table 1 the life cycle cost will be even less compared to the technology-oriented approach and the economic benefits of ergonomics design or redesign of the product can be measured through increasing; company's stocks value, selling, productivity and reducing accident and its related cost Hendrick [24]. The consequence of human-oriented design will lead to "good ergonomics is good economics" Hendrick (1996) [25].

The crucial aspects from an ergonomics point of view are how maintainability actors (designer, maintainability designer, and ergonomist) influenced the design of the system/product, design of work procedures, and work organizations in order to maintenance performances are free from accidents, incidents, and injuries. In order to integrate ergonomics in maintainability proactively, Bernard et al. [8] experimented with digital and physical mock-up simulation for assessing postures taken for a helicopter's eleven tasks maintenance performance in the situation of; standing, bending, lying down, and kneeling. They found a significant difference was between digital and physical simulations between acceptable postures, acceptable posture under conditions, and unacceptable posture, they stated the longest part of the performance was carried out in unacceptable posture. They concluded during maintainability analysis human factors/ergonomics need to be considered for various maintenance tasks, not individual tasks. During maintainability, design tasks can be categorized as physical, mental, or both. Tasks procedures for performance and its organization should consider both micro-ergonomics and macro-ergonomics principles and the shortage or absence of each one will not have optimal results.

\section{MAINTENANCE OPERATION}

Every engineered product due to the usage, aging, and failures will be degraded or become out of function. In order to keep the product in the intended function, maintenance operation is a crucial aspect, and as Blanchard [42] stated maintenance is required as a consequence of design. In the context of maintenance operations, the human factor needs to be applied in order to assure the maintainer's well-being and safety, which in turn results in, lesser maintenance cost, enhanced system supportabilities, enhances overall production, preventing production disruptions, and faster to repair. ISO-Standard [51] defines maintenance as, the combination of all technical, administrative, and managerial actions during the life cycle of an item intended to retain it in or restore it to, a state in which it can perform the required function. Maintenance is divided into two categories, preventive maintenance (PM) (time-directed) and corrective maintenance (CM) (breakdown) $[6,15]$. Details of each abovenamed categories are beyond the scope of this article.

\section{ERGONOMICS ISSUE IN MAINTENANCE AND ITS COST- SAVING}

Usually, maintenance management handbooks describe human factors/ergonomics from the helicopter's perspective. This kind of view will lead to many detailed ergonomics disciplines in order to apply several related tools at each stage of maintenance planning and performances. Application of ergonomics/human factor ensures the proper design features which relate to task performance for maintenance operators movements in their workplaces, Ben-Daya et al. [6]. System reliability is affected by multiple factors, near the top of the list are human factors, Diego et al. [16].

Many ergonomics improvements resulted in increasing both technical enhancements and economical profits gained from this intervention. In the handbook of engineering design U.S. Army [5], maintenance operation focused on human factors constraints. Shanmugam et al. [48] also applied ergonomics/human factors discipline in aircraft maintenance in order to improve maintenance performance in; hangar, workshops, task cards also designing tools and as Shanmugam conclude this discipline brought in benefits even to the area of aircraft design, operation, and maintenance. Rick Goggins [19] prepared a list of 250 companies and shown their costs benefits of different aspects of ergonomics improvements also, Hendrick [23] gave several examples of cost benefits of ergonomics in product design, from the petrochemical project, The Air Force C-141 aircraft system development and software design. Hendrick [24] in his article shows many 
pieces of evidence of the cost benefits of an ergonomics intervention in productivity. One of the companies he (Hendrick) mentioned "Forge shop manipulator" through ergonomics design could improve their productivity and the results they gained were; reducing whole-body vibration, reducing the noise level by $18 \mathrm{~dB}$, sick leave from $8 \%$ to $2 \%$, dropping maintenance costs by $80 \%$.

Many industry managers may think that ergonomics is an extra cost expense for their system. They may think ergonomics or human factors nowadays are nothing more than "common sense" and it is built in the design process Hendrick [24]. That is, this way of perception is or reveals on trusting to technology-oriented design rather than technology's operators oriented or human-oriented design. In the case of some discrepancies or decreases in their system performance is humans' fault. This way of thinking (common sense) can be a route of incorrect judgment and make decisions based on their pre-judgment. They may get used to and accepting of dealing with eventual accidents, incidents, or poor usability of their engineered product/system designed.

The benefits of considering ergonomics/human factors are how this science can increase the quality of people working life and this science had been shown enormous potential for improving the safety, health, and comfort of people that led to increased productivity for both humans and the system Hendrick [24]. The economic benefit of integrating ergonomics in the design process falls in three aspects:

1) employees see Table 2,

2) in materials and equipment,

3) increased sales, Hendrick [23].

As he stated these benefits can be instantaneous and also cost-saving for the system/product's entire life cycle time. $\mathrm{He}$ (Hendrick) notified also other ergonomics intervention benefits like reduced; scrap, equipment, production parts and materials, maintenance tools, and material and equipment damage.

\section{APPLICATION OF ERGONOMICS IN THE MAINTENANCE PROCESS}

International Ergonomics Association (IEA) [29] "Ergonomics (or human factors) is a scientific discipline that concerns with the understanding of interactions among humans and other elements of a system, and the profession that applies theory, principles, data, and methods for design in order to optimize human well-being and overall system performance". Application of this science in system/product design results in positive effects of ergonomics as well as economics in the system or product usage, good ergonomics is good economics [25]. The integration of micro and macro ergonomics in system/product design is a more effective (doing the right thing) and efficient (doing things right) way to handle human integration into the system.

Nowadays, in many maintenance operations task(s) instruction(s)/description(s) it is difficult to find out the description for a specific task performance that can cause fatigue (which is the result of muscle pain and awkward working posture) or is/are painful. Despite the fact that designers considering all safety standards for their designed system/product but lacking in human factors knowledge will cause problems to system/product, in other words, they do not know what they do not know, this is because designers mostly focus on the functionality of their engineered design [52]. In this context, human abilities in terms of physical and mental limitations may be missed during the entire design process.

Table 2

Summary of employees-related benefits

\begin{tabular}{|c|c|}
\hline Personnel-related benefits & Cost benefits \\
\hline Increased output per worker & Design in; workplace, hardware, software, and work system (macro-ergonomics) \\
\hline Reduced errors & $\begin{array}{l}\text { Increased productivity, fewer accidents, reduction in equipment damage, personnel injuries, and related } \\
\text { costs }\end{array}$ \\
\hline $\begin{array}{l}\text { Reduced accidents, injuries, } \\
\text { and illness }\end{array}$ & Savings in workers compensation insurance, saving in production, maintenance, and administration units \\
\hline Reduce training time & $\begin{array}{l}\text { Work system design in easier to perform function and process, less turnover, reduced lost time because } \\
\text { of accidents and injuries, less absenteeism, fewer workers to perform a given function, } \\
\text { and ergonomicsally designed training program }\end{array}$ \\
\hline Reduced skill requirements & $\begin{array}{l}\text { Improved work system process and related task leads to reducing skill, reduced training, and saving in } \\
\text { salary }\end{array}$ \\
\hline Reduced maintenance time & $\begin{array}{l}\text { Many times ergonomics improvements to jobs, workplace, equipment, } \\
\text { or work systems lead to reducing maintenance performances, fewer maintenance operators, saving salary } \\
\text { consequently reduced maintenance costs }\end{array}$ \\
\hline Reduced absenteeism & Reduction of personnel replacement, saving in salary, and increasing productivity \\
\hline Reduced turnover & Improved employees' quality of working life, reduced employees turnover cost \\
\hline
\end{tabular}

Source: [34]. 
Metaphorically, they are trapped in a situation called cognitive tunneling. As Almeida [3] described, "Cognitive tunneling, also known as cognitive capture is an in-attentional blindness phenomenon where one becomes hyperfocused on some variable other than the present environment". In order to exit from the cognitive tunnel, it is essential to consider an ergonomist as a part of the design team. Ergonomists as a part of the design team or as a consultant can use several tools from their domain in order to identify risks and simulating/calculating the consequences of risks, evaluating future task performance in conjunction with maintenance operators' physical and mental abilities.

Usually, maintenance tasks in industries demanding or requiring vigorous physical effort (manual handling) and having awkward postures because of incommodious working conditions (position of work in space, angle or position of work, vision, and environment). These situations will lead to the risk of work-related musculoskeletal disorders (MSDs) if task performance is out of the human body power zone (above the knees, below the shoulders, and close to the body) [27]. Even there is no reason to assume every task that is in the human power zone is safe.

A report of the European Agency for Safety and Health at Work EN 4 [43], stated, musculoskeletal disorders (MSDs) or injuries are related to muscles, tendons, joints, nerves, ligaments, and skeletons. These injuries are the effect of the work or workplace where the task is carried out, it is also reported twenty-five percent of employees complain of backache moreover, twenty-three percent reported muscular pain [43]. These figures indicate the musculoskeletal disorders (MSDs) are the major cause and are the most common work-related health problem which resulted in sick leaves in the European Union (EU). It reported 498000 workers suffering from work-related musculoskeletal disorders (19\% lower limbs, $41 \%$ upper limbs or neck, and $40 \%$ back) that resulted in 6.9 million working days lost in 2018 [22]. Swedish Work Authority (Arbetsmiljöverket) [4] published the percentage of women and men who reported pain each week in the upper parts of the body, back/neck, shoulder, or arms in 1991-2011, see Fig. 1.

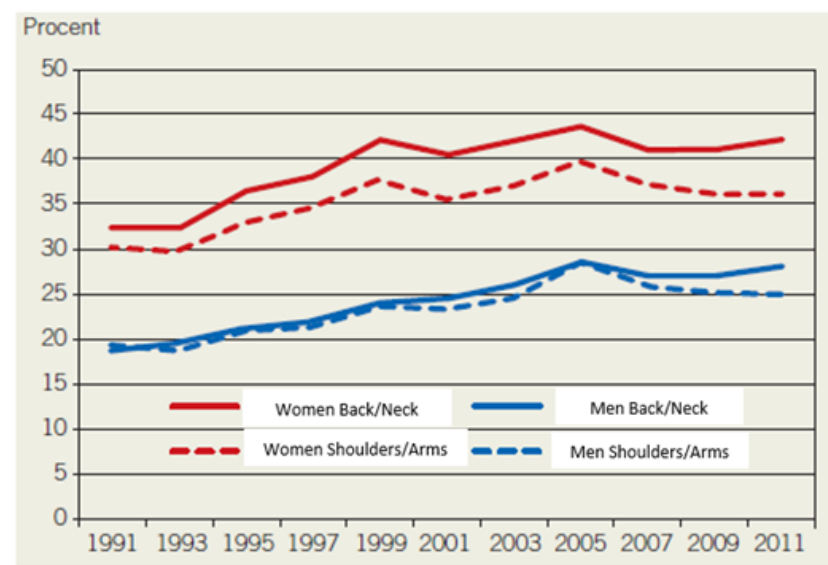

Fig. 1 Physical problems for every week in 1991-2011

\section{METHODOLOGY FOR EVALUATING PHYSICAL WORK- LOAD}

In order to assure maintainers' safety and wellbeing different risks (e.g. job factors, personal factors, and organizational factors) assessments and risks analysis are needed to carry out before maintenance operations start [21]. These two (assessing and analyzing risks) are the core issues that are prerequisites to be considered during maintainability design and maintenance planning.

There are several classical tools for evaluating physical workload. Rapid Entire Body Assessment (REBA), is used for analyzing postures taken in order to evaluate musculoskeletal injuries [26]. Rapid Upper Limb Assessment (RULA) focuses on upper extremities and neck/shoulder when sitting or standing [38]. ALLA is used for agricultural lower limb assessment [33]. OWAS is a practical method for identifying and evaluating poor working postures [31]. Quick Exposure Check (QEC) is used for assessing exposure to risk factors for work-related musculoskeletal disorders [18]. Posture, Activity, Tools and Handling (PATH) are used for ergonomics analysis in the area of construction and other work that are non-repetitive [9].

In this study, 3D Static Strength Prediction Program (3DSSPP) is used. This tool is using for evaluating/analyzing the load on the back, shoulder, wrist, elbow, torso, hip, knee, and ankle. 3D SSPP program shows the results in form of bar graphs the percentage of the population that has the current anthropometry data has enough strength to perform the required load and the percentage of maximum voluntary contraction for each above-named joint. The 3DSSPP is most useful in the analysis of slow movements that are used in heavy materials handling tasks and biomechanical computations when assumed that the effects of acceleration and momentum are negligible. Instructions explain that task performance should be divided into a sequence of static postures in order to analyze each individual posture. Mathematical models and occupational biomechanics issues that are referred to in this program are found in "Occupational Biomechanics $4^{\text {th }}$ Edition" by Chaffin et al. 2006 [11].

The 3D SSPP program is commonly used as an ergonomics evaluation tool in scientific studies measuring workload Paul S. Adams in his study of "Selecting Ergonomics Analysis Tools [1] described the 3DSSPP program as being a useful tool for simulating the initial design of ergonomics actions, on top of that, this program is used for simulation and to assess hypothetical solutions.

In a study for compression on L4-L5 for firefighters compared different ergonomics tools, it was stated that 3DSSPP DHM (digital human models) have allowed for an in-depth investigation of injury risks when firefighters performing lift and carry the hose Kajaks 2017, [30]. 3D SSPP uses over 2000 in U.S. and international sites by an ergonomist, researchers, engineers, those who evaluating a job, job designer, and physical as well as occupational therapist, Rong et al. (Multiple tasks input tool for 3D Static Strength Prediction Program) [28]. We can conclude that 
the 3D SSPP is a valid tool to simulate and give valid recommendations for improving the workplace and reducing low back compression.

\section{CASE STUDY}

In one maintenance workshop, the maintainers' physical workloads were investigated. A Nordic standard questionnaire was used and it is shown six and four operators (out of nine) claimed they have pain in the upper and lower back pain respectively and seven declared having a problem with their shoulder. Operators' daily works were rotating at different workplaces, and one of their tasks was lifting two heavy objects with both hands( see Figure 2). Each object weighed 18 kilograms that should lift from the floor and put to the intended place (this study carried out only on lifting objects not carrying and putting on the intended place). At the place of lifting objects, their performance was filmed and then it converted into pictures.

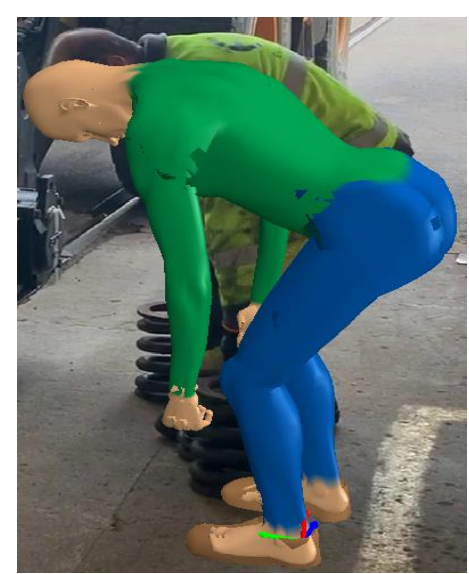

Fig. 2 Avatar matched with operator posture

\section{RESULTS}

A combination of risk factors normally interacts with each other, consequently, it creates comprehensive risks for upper limb disorders (ULDs). Some of these risk factors are, repetitive tasks, force, working in awkward postures, duration of work in an awkward posture, and working environment that cause work-related to musculoskeletal disorders (MSDs). Fig. 3 shows posture taken in order to lift 18 kilograms of spring with each hand in different axis $(\mathrm{Z}, \mathrm{Y}$, and $\mathrm{X})$ in positive directions.

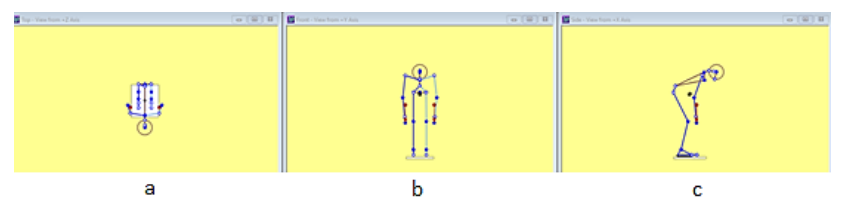

Fig. 3 (a) Top-View $+Z$ axis, (b) Front-View $+Y$ Axis, (c) Side-View $+X$ Axis

Fig. 4 shows the back compression in the taken posture and lifting springs.

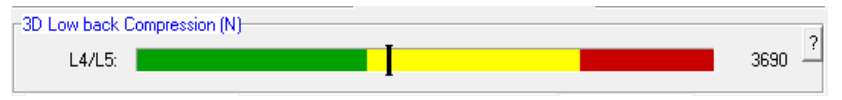

Fig. 4 Low back compression in Newton
In order to understand the low back compression effects on the spine during manual handling works, it is necessary to describe two terms in the unit of Newton, Action Limit (AL) and Maximum Permissible Limit (MPL) [34].

According to NIOSH quantifications load force on the back, the action limit (AL) is the amount of 3400 Newton or [350 kg or (770 lb.)] compression force on the L5/S1 (Lumbar spine 5/Sacral spine 1) disc can be tolerated by most young, healthy workers. It is also stated up to 350 kilograms over $99 \%$ of men and over $75 \%$ of women can lift the loads. On the other hand, Maximum Permissible Limit (MPL), made a firm decision as, biomechanical compression forces on the L5/S1 disc are not tolerable over 6400 Newton or [650 kg (1430 lb.)], and only less than $1 \%$ of women and about $25 \%$ of men workers have the muscle strengths also [20], it is shown work-related low back disorders (WLBD) at MPL level is eight times higher than at AL level [53].

In this program, the default limit value between the green and yellow regions is the NIOSH action limit $(A L)$ value, and the default limit is the transition from yellow to the red regions is the NIOSH upper limit (MPL).

Fig. 4 shows the load on the back because of the posture taken is located in the yellow area and indicates 3690 Newton force/pressure on the operator's low back. According to NIOSH [20], it is necessary to investigate administrative controls when the conditions exceeding the AL limit ( $3400 \mathrm{~N})$. Administrative control refers to whether workers are weak or unfit for the heavy lifting loads or strong workers or fit workers are well trained in order to avoid certain lifting posture and/or activities that are known to increase the hazard level.

Fig. 5 shows the results of joints' strength capabilities in; wrist, elbow, shoulder, torso, hip, knee, and ankle. This figure highlighted the strength of, torso, hip and ankle are less than $99 \%$ because of the posture situation.

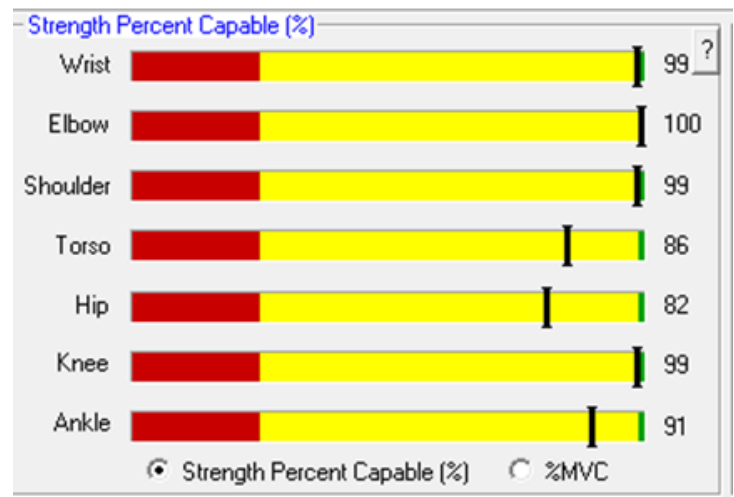

Fig. 5 Strength percent capability of joints

And, Fig. 6 highlighted the fatigue in wrist and shoulder.

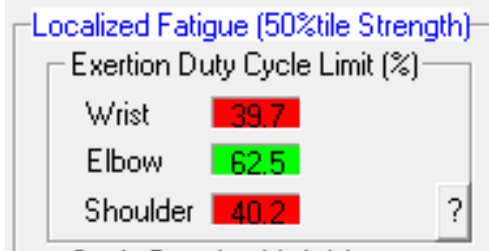

Fig. 6 Localized fätigue 
Fatigue defined as a failure to maintain the required or expected force in muscle, and the force of a voluntary contraction is graded according to both the tension generated in each muscle fiber and the number of fibers recruited, and one the possible meaning of fatigue also is impaired intellectual performance Ciba foundation symposium [44]. It causes loss of muscles force and slowing down muscle's capability for producing contraction [17], it is also shown slowing down body movement [14], decrements in performance [37], and consequently, when the muscles get fatigued they are no longer able to do effective work [20]. 6 localized fatigue on wrist and shoulder due to the posture, load and exerted force duration.

\section{RECOMMENDATIONS}

As the essence of the work performance requires taking the posture as it is shown in Fig. 2 and at the same time lifting an 18-kilogram spring with each hand that caused 3690 Newton compression on the low back, the best solutions are either to reduce the weight, redesign workplace in form standing posture, or using lifting aids as NIOSH [20] also recommended.

Usually, the object's weight cannot be changed therefore other two options can be considered as improvement factors.

Concerning the redesign workplace, a study that did by the Association of American Railroad (AAR) (1989) [45] used the University of Michigan Center for Ergonomics computer model that calculated back compression at bending lift posture at Union Pacific Railroad's (UP) shop operation. The results of calculations shown 1319 lbs. compression on the back and according to $\mathrm{NIOSH}$, this compression was between the action limit ( $A L)$ and maximum permissible limit (MPL) or in the area of the yellow zone as shown in Fig. 7.

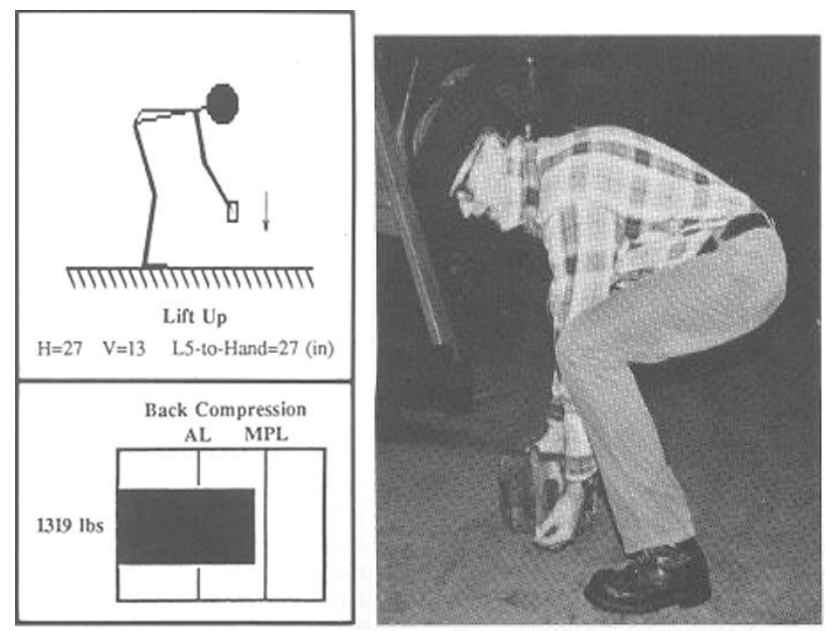

Fig. 7 Posture taken during bending lift (Pictures adapted from $A A R)$

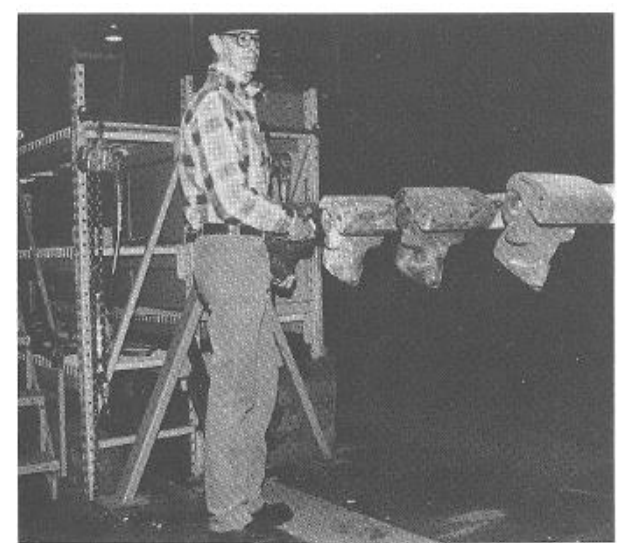

Fig. 8 A redesigned workplace (Adapted AAR)

As a result of redesigning the workplace as shown in Fig. 8 in standing lifting posture at UP shop operation, their productivity increased from 1564 cars to 2900 in three years and the value of car repaired increased from $\$ 8935$ million to $\$ 12000$ million in three years. The company calculated the ratio of cost-benefit that reveals from 1 to 10 . Table 3 shows the effect of improvement that resulted in reducing back injuries and its benefits in the UP Railroad's shop operation.

Table 3

Results of implementing Back-injury reduction program (Adapted AAR)

\begin{tabular}{lcccc}
\hline & $\mathbf{1 9 8 5 *}$ & $\mathbf{1 9 8 6}$ & $\mathbf{1 9 8 7}$ & $\mathbf{1 9 8 8}$ \\
\hline Total incidents & 33 & 23 & 10 & 12 \\
Reportable incidents & 29 & 10 & 2 & 7 \\
Lost-time incidents & 12 & 1 & 0 & 0 \\
Back injuries & 9 & 0 & 0 & 0 \\
Lost days & 579 & 11 & 0 & 0 \\
Restricted days & 194 & 15 & 2 & $4 * *$ \\
$*$ 1985 data are typical & of data for the previous & 4 \\
$* *$ Increase is in non-back-related minor injury incidents.
\end{tabular}

In order to reduce low back compression as it shown in Fig. 4 lifting assistance (lift arm hoist) can be considered as a solution for, they can perform their task in standing posture (natural posture), see Fig. 9 In order to use lifting aid as shown in Fig 10 operators grip the maneuvering panel and pressing the button for lowering the hook (or any kind of gripper). After adjusting the griper/hook to the load, operator should press lifting up button to perform the task.

Using lifting aid in natural posture was simulated, and the results of low back compression reveal in the green area only $178 \mathrm{~N}$ (no burden in hand) (see Fig. 11), strength capability of joints all are in the acceptable situation (see Fig. 12), and no indication of fatigue as shown in Fig. 13 for the wrist, elbow, and shoulder. Consequently, this task can perform by over $99 \%$ of men and over $75 \%$ of women NIOSH [11]. 


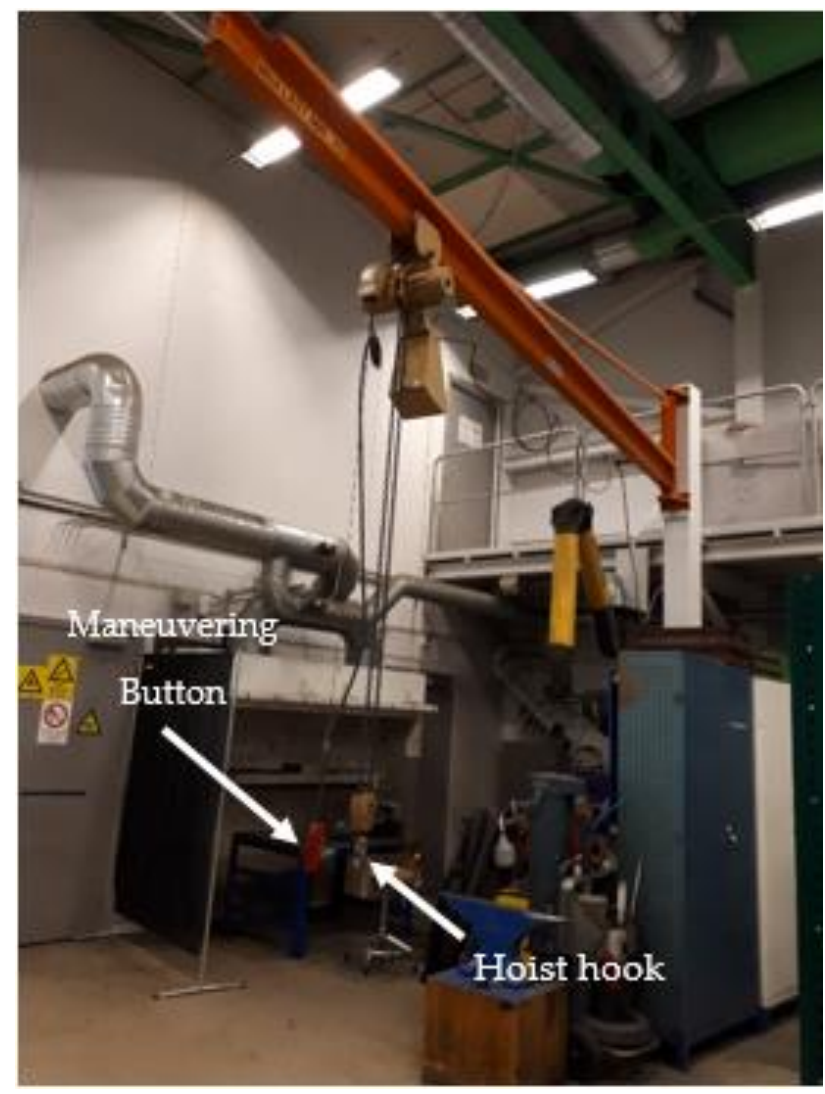

Fig. 9 Hoist

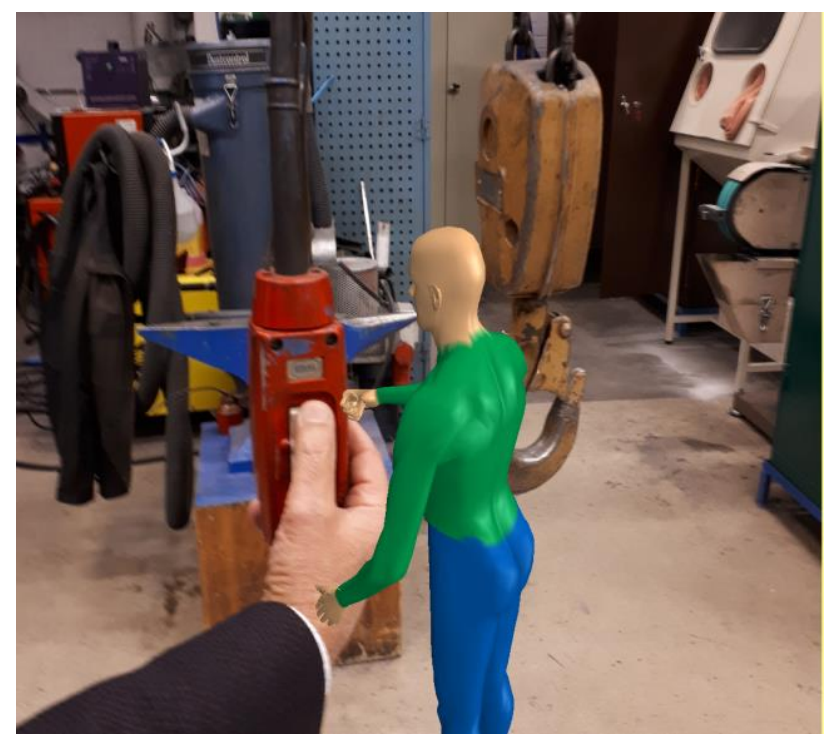

Fig. 10 Standing in the natural posture

3D Low Back Compression (lb) L4/L5:

Fig. 11 Low back compression in Newton using lifting aid

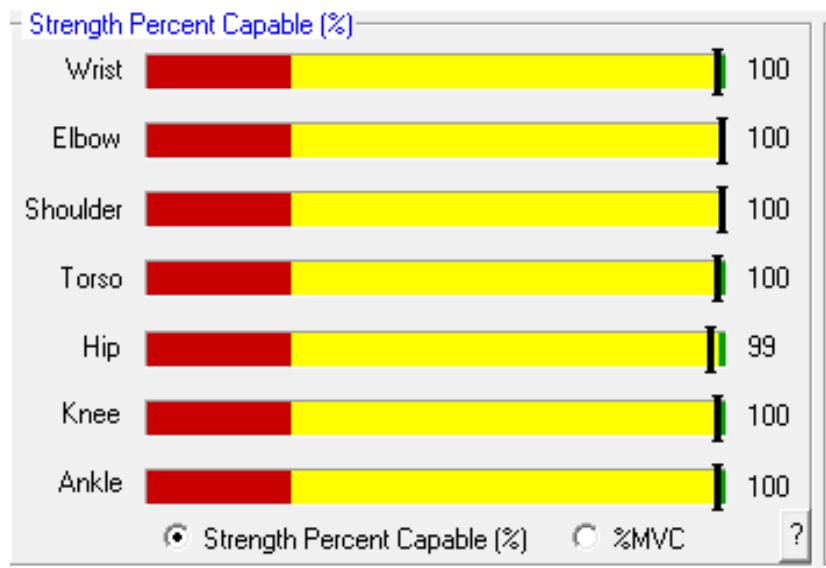

Fig. 12 Strength percent capability using lifting aid

Localized Fatigue [50\%tile Strength]
$\left.\begin{array}{|cc|}\text { Exertion Duty Cycle Limit [\%] } & \\ \text { Wrist } & 100.0 \\ \text { Elbow } & 100.0 \\ \text { Shoulder } & 64.0\end{array}\right]$

Fig. 13 Localized fatigue using lifting aid

\section{DISCUSSION}

As the literature survey described work related to musculoskeletal disorders is common in maintenance operations. This is due to the maintainability design process in which designers overlook work performance and work organization for a specific task. The focus of this study was how posture has taken due to the nature of work for lifting objects that can affect low back compression. Even operators who were trained on lifting techniques still postures taken indicate after a while that operators do not follow the training. Working at this posture for a prolonged time has shown to result in fatigue and serious back pain. Fatigue will have negative effects on productivity, a longer time for maintenance performance or increasing mean time to repair (MTTR), reduces quality, higher cost, and can increases errors. As Dhillon [13] stated "Maintainability is more dependent upon the action of the operating and maintenance personnel, and to a greater extent involves the interactions between people and machines. It, therefore, depends more on human factors than does reliability. Failure to consider human factors carefully during equipment design can lead to increased maintenance problems and reduced effectiveness and readiness".

In maintainability, and maintenance planning handbooks, many cost considerations described regarding; technical, 
administrative, logistics, ... issues, but there is a lack of cost or cost-benefit calculations for ergonomics/human factors interventions during the maintainability design process in their chapters for safety and human factors considerations.

This can be assumed, workers in many situations have to adapt themselves to technology-oriented design.

Due to the nature of their work, the results of the analysis reveal why they have pain in their back and shoulders. If during maintainability design process ergonomist was involved, all performances could have been simulated and designers could have redesigned workplace and/or lifting aid could have been prepared, and workers' health were assured.

\section{CONCLUSION}

Repetitive tasks, be forced to take an awkward posture and its duration, a workplace that causes musculoskeletal disorders, and other environmental risks are factors that can interact with each other in which the combination of them lead to musculoskeletal disorders. Taking discomfort posture and at the same time exerting efforts cause also pain and fatigue. These two symptoms influence to the lesser productivity, increasing mean time to repair (MTTR), increasing downtime, cause poor quality in maintenance activities, increase errors, and also leads to social costs.

All these problems are due to the design because of mismatching of the system's work demand and human characteristics. Designers think (because they are human) they understand human and end-users of their system/product should have the same understanding of the logic of the design, or system/product buyer think that ergonomics or human factors issues are common sense, it should be built-in the design, therefore investing on that is unproductive.

Lack of sufficient ergonomics/human factors understanding for both owners and designers will end-up in poor maintainability design and maintenance performance, which in turn leads to decreasing the overall equipment effectiveness (OEE). If OEE cannot perform based on designers' logical calculation, operators should not be blamed because of that, rather this is the designers' fault of the poor design, which leads to deficiencies in the system/product's functioning.

If designers or system owners come to know deficiencies in their system are related to human factors and look for ergonomics improvement they should be known improvements will be suboptimal because the design was founded on technology-oriented. Therefore, the sooner ergonomist participation in the design process not only the more humanized system/product will be also this participation will lead to the cost benefits for the entire system/product life cycle time.

The purposes of maintainability are safety, ease, accuracy, and economy for maintenance actions and those who are performing maintenance actions will be affected by all these four named elements. As literature reveals maintainability plan is directly related to human characteristics (abilities and limitations) who will be performing the maintenance operation.

In the above-named literature about maintainability, all authors stressed the need for collaborations between maintainability engineers and ergonomist/human factors engineers.

In this context, the cost of human factor or ergonomics is needed to be in the innate of the maintainability design process as like the other cost considerations.

The system is not only the sum of its collected parts, but it is also more than that when the system/product is in function. Functioning is an emergent property of the system/product which each individual element does not have that property. Overlook to human factor/ergonomics issues as one part of the system/product functionality is failing to understand or to comprehend the concept of an emergent property of the designed system/product. Therefore, during the design of the engineered system or product, it is crucial to set the user as the focal point in the core of the maintainability design process and having a palindromic perception about human in/and system for the whole maintainability design process.

\section{REFERENCES}

[1] P.S. Adams. "Selecting ergonomics analysis tools", in Proc ASSE Professional Development Conference and Exposition, American Society of Safety Engineers, 2005.

[2] D. Alexander. The Cost Justification Process. Auburn Engineers. Inc, Auburn, Alabama, 1999.

[3] D. Almeida. (2017). Exit the Cognitive Tunnel. Available: http://davidalmeidamd.com/category/cognition/.

[4] Arbetsmiljöverket. (2012). Physical problems for every week in 1991-2011. Available: https://www.av.se/globalassets/filer/statistik/arbetsmiljo statistik-arbetsmiljon-2011-rapport-2012_04.pdf.

[5] I. Bazovsky. Engineering design handbook-Maintainability engineering theory and practice. US Army Materiel Command, 1976.

[6] M. Ben-Daya, U. Kumar and D.N.P. Murthy. Introduction to maintenance engineering: modelling, optimization and management. John Wiley \& Sons 2016.

[7] F. Bernard. "Consideration of human factor in aeronautical maintainability" in Annual Reliability and Maintainability Symposium (RAMS), IEEE, 2017.

[8] F. Bernard. "Virtual reality simulation and ergonomics assessment in aviation maintainability" in Cong. of the Int. Ergonomics Association, Springer, 2018.

[9] B. Buchholz. "PATH: A work sampling-based approach to ergonomics job analysis for construction and other nonrepetitive work" Applied Ergonomics, vol. 27(3), pp. 177187, 1996.

[10] Centers for Disease Control and Prevention(CDC). "Fatal injuries among grounds maintenance workers: United States, 2003-2008. Morbidity and mortality weekly report MMWR" Centers for Disease Control and Prevention, 2011.

[11] D.B. Chaffin, G.B. Andersson, and B.J. Martin. Occupational biomechanics. John Wiley \& Sons, 2006.

[12] D.B. Chaffin and K.S. Park. "A longitudinal study of lowback pain as associated with occupational weight lifting factors" American Industrial Hygiene Association Journal, vol. 34(12), pp. 513-525, 1973. 
[13] B.S. Dhillon. Engineering Maintainability: How to Design for Reliability and Easy Maintenance. Gulf Publishing Company, 1999.

[14] D. Fang. "An experimental method to study the effect of fatigue on construction workers' safety performance" Safety science, vol. 73, pp. 80-91, 2015.

[15] C. Franciosi, B. lung, S. Miranda and S. Riemma. "Maintenance for sustainability in the industry 4.0 context: A scoping literature review" IFAC-PapersOnLine, vol. 51(11), pp.903-908, 2018.

[16] D.P. Galar and U. Kumar. Maintenance audits handbook: A performance measurement framework. CRC Press, 2016.

[17] S.C. Gandevia, G.M. Allen and D.K. McKenzie. "Central Fatigue," in Advances in Experimental Medicine and Biology, vol 384. Springer, Boston, 1995.

[18] D. Geoffrey. "The development of the Quick Exposure Check (QEC) for assessing exposure to risk factors for work-related musculoskeletal disorders" Applied Ergonomics, vol.39(1), pp. 57-69, 2008.

[19] R.Goggins, Ergonomics cost benefit case study collection. Available: https://www.pshfes.org/cost-calculator.

[20] Health Division of Biomedical and Behavioral Science. "Work practices guide for manual lifting (No. 81-122)." US Department of Health and Human Services, Public Health Service, Centers for Disease Control, National Institute for Occupational Safety and Health, Division of Biomedical and Behavioral Science, Cincinnati, OH, pp. 198. 1981.

[21] Health, Executive Safety. "Performance Influencing Factors (PIFs)." Health and Safety Executive: UK, 2019.

[22] Health, Executive Safety. "Work related musculoskeletal disorder statistics (WRMSDs) in Great Britain, 2019." Health and Safety Executive: UK, 2019.

[23] H.W. Hendrick. "Determining the cost-benefits of ergonomics projects and factors that lead to their success." Applied ergonomics, vol. 34(5), pp. 419-427, 2003.

[24] H.W. Hendrick. "The ergonomics of economics is the economics of ergonomics," Proc. Human Factors and Ergonomics Society Annual Meeting, SAGE Publications, Sage CA: Los Angeles, CA, 1996.

[25] H.W. Hendrick. "Ergonomics is good economics." Human Factors and Ergonomics Society, Citeseer, 1996.

[26] S. Hignett. and L. McAtamney. "Rapid Entire Body Assessment (REBA)." Applied Ergonomics, vol. 31(2), pp. 201-205, 2000

[27] J. Howard and L. Welsh. Ergonomics Guide for Manual Material Handling. DHHS (NIOSH) Publication No. 2007131, Cincinnati, OH 45226: California, Department of Industrial Relations, 2007.

[28] R. Huangfu. Multiple tasks input tool for 3D Static Strength Prediction

Program.

Available:https://www.researchgate.net/profile/RongHuangfu/publication/281420858_Multiple_tasks_input_t ool_for_3DSSPP_3D_Static_Strength_Prediction_Progra $\mathrm{m} /$ links/55e661fa08aede0b57376c3e/Multiple-tasksinput-tool-for-3DSSPP-3D-Static-Strength-PredictionProgram.pdf.

[29] W. Karwowski. "The International Ergonomics Association (IEA)," In International Encyclopedia of Ergonomics and Human Factors, vol. 3. CRC Press, 2006, pp. 170-173.
[30] T. Kajaks. "Virtual ergonomics and gaming technology for posture assessment: From automotive manufacturing to firefighting." Doctoral dissertation, McMaster University, Hamilton, Ontario, 2017.

[31] O. Karhu, P. Kansi and I. Kuorinka. "Correcting working postures in industry: A practical method for analysis." Applied Ergonomics, vol. 8(4), pp. 199-201, 1977.

[32] W.M. Keyserling. L. Punnett and L.J. Fine, "Trunk posture and back pain: identification and control of occupational risk factors." Applied Industrial Hygiene, vol. 3(3), pp. 8792, 1988.

[33] Y. K. Kong, "Comparisons of ergonomics evaluation tools (ALLA, RULA, REBA and OWAS) for farm work." International Journal of Occupational Safety and Ergonomics, vol. 24(2), pp. 218-223, 2018.

[34] S. Kumar. Biomechanics in Ergonomics. $2^{\text {nd }}$ ed., CRC Press, Taylor \& Francis Group, 2007.

[35] S. Lind. "Accident sources in industrial maintenance operations. Proposals for identification, modelling and management of accident risks" VTT, 2009.

[36] L. Ma. "A new muscle fatigue and recovery model and its ergonomics application in human simulation". Virtual and Physical Prototyping, vol. 5(3), pp. 123-137, 2010.

[37] G. Matthews and P.A. Hancock. The handbook of operator fatigue. CRC Press, 2017

[38] L. McAtamney and E.N. Corlett. "RULA: a survey method for the investigation of work-related upper limb disorders" Applied Ergonomics, vol. 24(2), pp. 91-99, 1993.

[39] M. Milczarek. Joanna Kosk-Bienko,European Agency for Safty and Health at Work: A Statistical picture, 2010, Available:

https://osha.europa.eu/en/publications/maintenanceand-occupational-safety-and-health-statistical-picture

[40] MIL-HDBK-470A. Designing and Developing Maintainable Products and Systems, Volume I., Department of Defence, USA, 1995.

[41] T. Morken. I.S. Mehlum and B.E. Moen. "Work-related musculoskeletal disorders in Norway's offshore petroleum industry" Occupational Medicine, vol. 57(2), pp. 112-117, 2007.

[42] E.L. Peterson. D.C. Verma. and B.S. Blanchard. Maintainability: $A$ key to Effective serviceability and Maintenance Management. vol. 13, John Wiley \& Sons, New York, 1995.

[43] Z. Podniece. S. Heuvel and B. Blatter. Work-related musculoskeletal disorders: prevention report, European Agency for Safety and Health at Work, 2008.

[44] R. Porter and J. Whelan. Human muscle fatigue: physiological mechanisms, vol. 82, John Wiley \& Sons, 2009.

[45] RAILROADS, A.O.A., Preventing Back Injuries. USA, 1989, pp. 16-17.

[46] D. Riley, Manual Handling in the Rail Sector in South Wales. $\mathrm{HSL} / 2006 / 53$ 2006, Available: https://www.hse.gov.uk/research/hsl_pdf/2006/hsl0653. pdf

[47] C. Sedlatschek. A European Campaign on Safe Maintenance, in HEALTHY WORKPLACES. European Agency for Safety and Health at Work, Belgium, 2011, pp. 56. 
[48] A. Shanmugam and T.P. Robert. "Human factors engineering in aircraft maintenance: a review" Journal of Quality in Maintenance Engineering, vol. 21(4) pp. 478505, 2015.

[49] L.P. Singh. "An investigation into work postures of workers engaged in casting industry: a study in India" Asian Journal of Managerial Science, vol. 1(1), pp. 17-22, 2012.

[50] N.A. Stanton. Handbook of human factors and ergonomics methods. CRC press, 2004.
[51] Swedish standard institute. "13306 Maintenance Maintenance terminology, in Maintainability" 2017.

[52] K. Teymourian. D. Seneviratne and D. P. Galar. "Ergonomics Contribution in Maintainability" Management Systems in Production Engineering, vol. 25(3), pp. 217-223, 2017.

[53] T.R. Waters. "Revised NIOSH equation for the design and evaluation of manual lifting tasks" Ergonomics, vol. 36(7), pp. 749-776, 1993.

\section{Kiumars Teymourian}

Luleå University of Technology

Division of Operation and Maintenance Engineering

Luleå, 971 87, Sweden

e-mail: kiumars.teymourian@ltu.se

\section{Phillip Tretten}

Luleå University of Technology

Division of Operation and Maintenance Engineering

Luleå, 971 87, Sweden

e-mail: phillip.tretten@ltu.se

\section{Dammika Seneviratne}

TECNALIA, Basque Research and Technology Alliance (BRTA)

Derio-Vizcaya, 48170, Spain

e-mail: dammika.seneviratne@tecnalia.com

\section{Diego Galar}

Luleå University of Technology

Division of Operation and Maintenance Engineering

Luleå, 971 87, Sweden

TECNALIA, Basque Research and Technology Alliance (BRTA)

Derio-Vizcaya, 48170, Spain

e-mail: diego.galar@ltu.se 